\title{
Modos de Conocimiento: la lección de Castaneda
}

\author{
Ana María Ramo y Affonso
}

Resumen: En este ensayo, hacemos una reflexión sobre la práctica antropológica y el impacto de la obra de Carlos Castaneda en la relación entre la ciencia y la magia, que entre otras situaciones, la antropología representa. Castaneda conoce la imposibilidad de explicar el conocimiento de Don Juan, el chamán que es su informante y su maestro, fuera de sus propios términos y es por eso que la antropología de Carlos Castaneda cuestiona las explicaciones científicas de la magia. Las palabras de Don Juan sobrepasan el texto antropológico de Castaneda y llegan hasta nosotros con una fuerza que ha cautivado a millares de lectores, dentro y fuera de la antropología.

Palabras clave: Chamanismo, antropología, modos de conocimiento, realidad, transformación.

Enviado a dictamen: 10 de febrero de 2010

Aprobación: 18 de mayo de 2010

Revisiones: 1

Ana María Ramo y Affonso, maestra en Antropología Social por la UFMGUniversidad Federal de Minas Gerais, Brasil. Correo electrónico: elfanark@ hotmail.es.
Abstract: In the present essay, we reflect about the anthropological practice and the impact of Carlos Castaneda's work in the relation between science and magic that anthropology (among other things) represents. Castaneda knows the impossibility to explain Don Juan's knowledge, the shaman that is his "informant" (and his master), out of his own terms, and this is why the Carlos Castaneda's anthropology comes to shake the scientific explanation of magic. Don Juan's words overflow Castaneda's anthropologic text and come to us with a strength that has enchanted thousands of readers, inside and outside anthropology.

Keywords: Shamanism, anthropology, ways of knowledge, reality, transformation.

$\mathrm{E}$ n este trabajo intento mostrar cómo la opción de Carlos Castaneda de utilizar los "términos" de Don Juan para expresar sus propios postulados, es un modo de "hacer" antropología que permite no sólo una aproximación al otro que queremos entender, sino que también nos posibilita un modo diferente de analizar nuestros propios principios, nuestro propio mundo, nuestra descripción. Es precisamente esta la descripción que aquí analizo, y que sirve de punto de encuentro entre antropólogos, sociólogos, filósofos y chamanes, puesto que sus trabajos, sus textos, sus palabras y sus 
conceptos muestran tener muchos puntos en común. Carlos Castaneda, entre otros, muestra que es posible una antropología que, más que producir explicaciones, procure ser un vehículo de expresión de modos de conocimiento y experimentación del mundo que difieren de los nuestros. Una antropología preparada para dialogar y dejar de reducir los postulados de los pueblos que estudia a ejemplos o excepciones, que confirmen sus propias reglas. Es sin duda una tarea difícil que requiere una transformación y flexibilización conceptual que, por otra parte, ya hace algún tiempo que se está dando, como demuestran los autores citados. Se trata de un proceso que exige todavía muchos esfuerzos de nuestra parte, principalmente en lo que se refiere a los estudios sobre chamanismo; un proceso que nos impulsa a continuar en esta línea de investigación, con nuestras aportaciones al modo conceptual de lo que aquí llamamos pasaje, con la intención de proponer alternativas al modo del intervalo, de la oposición e, incluso, de la dialéctica y de la contradicción, que han prevalecido en la práctica antropológica y en la episteme occidental como un todo.

Considero que la fluidez conceptual, la fluidez del pensamiento y del entendimiento, el modo fluido, en fin, del pasaje, son necesarios para cualquier aproximación antropológica a los diversos postulados de lo que se denomina chamanismo. En el contexto del presente análisis, solamente a partir de este punto de vista, de esta opción conceptual, parece posible aceptar como hecho, y no sólo como valor, la "descripción mágica del mundo", tal como postulada por Don Juan (Castaneda, 2001c: 15). Dado que los modos de acción de los chamanes sobrepasan cualquier tentativa de reducción o definición, la intención principal de este trabajo es mostrar, con la ayuda de Don Juan, que no es posible entender y ni siquiera imaginar antropológicamente el chamanismo, reduciéndolo a modos simbólicos de representación de una realidad que no cesa de huir. El chamanismo es un término que agrupa un conjunto de múltiples prácticas de invención, construcción, expresión, imaginación y/o experimentación de los posibles vehículos que son los cuerpos de los chamanes; mucho más instrumentos de comunicación, que sujetos u objetos de interpretación o representación.

Don Juan, el informante de Castaneda, es un brujo que pertenece, según él mismo cuenta, al linaje de los brujos del México Antiguo. La relación entre Castaneda y Don Juan, entre maestro y aprendiz, entre antropólogo e informante es un punto central en la presente argumentación, puesto que tal relación provoca reflexiones importantes para la práctica antropológica al introducir un modo de conocimiento, o un modo de hablar de los hechos, que abre una brecha en el discurso occidentalmente organizado; una brecha por la cual se introducen otros modos de conocimiento, modos que el texto antropológico se esfuerza por digerir. La antropología es un vehículo de mediación, de dialéctica entre culturas y naturalezas, mundos y pensamientos.

La humildad de la antropología de Castaneda se verifica cuando él asume la imposibilidad de comprender y juzgar el conocimiento de Don Juan a partir de su propio punto de vista y de los sentidos que éste produce. Reflexionar respecto de este punto de vista, de este modo de producción de sentido, es uno de los objetivos del presente artículo, en el que intentaré que autores de diferentes filiaciones teóricas se comuniquen a través de los escritos de Castaneda y de las enseñanzas de su maestro Don Juan, buscando una ventana abierta desde la que poder observar aquello que quedó fuera de "la razón occidental", pero permaneció en los márgenes de una cierta antropología, como una fuerza escondida esperando la oportunidad de aparecer, o mejor aún, esperando que el antropólogo desaparezca con la fuerza de su figura y su razón y, como por arte de magia, haga aparecer otra razón que muchos se atreven a llamar de irracionalidad y que suprime la distinción entre materia y pensamiento, acción y racionalización, lo sensible y lo inteligible.

Nuevas formas difunden nuevos conceptos. Incluso cuando su cultura lo sitúa en el lugar del sujeto que 
observa, entiende y explica un objeto, al antropólogo siempre se le escapa alguna imagen de ese otro que encuentra y pretende identificar. Los informantes hablan en las entrelíneas de la antropología clásica, hasta que sus conceptos comienzan a adquirir relevancia conceptual, antropológica y filosófica para los antropólogos contemporáneos, lectores de los clásicos, que consiguen descubrir la figura en esas entrelíneas, en lo todavía no dicho. En este proceso surgen nuevas figuraciones, una proliferación de posibles.

Tratar el tema de la relación entre diversos modos de conocimiento, diversos modos de pensamiento y de acción, supone, en este caso, cuestionar la relación con la magia y sus prácticas que la antropología, en su tentativa de aproximarse a la supuesta fidelidad de la ciencia, reclama para sí. Castaneda experimenta en carne propia esta relación al aproximarse a Don Juan con la intención de realizar un trabajo científico sobre el uso mágico de ciertas plantas psicotrópicas, en un caso, y plantas de poder, en otro. Aunque cree ser él quien elige a Don Juan para ser su informante, es este último quien elige a Castaneda para ser su aprendiz, para "acomodarlo en la cognición" de los chamanes del México Antiguo (Castaneda, 2000: 33). Como diría Viveiros de Castro (200la: 19), Castaneda "entra en el pensamiento (otro) por la experiencia real", y esta entrada lo transforma. ${ }^{1}$ Se trata de una transformación lenta y difícil:

Transformación que implica mudar el modo de estar en el mundo y conocer la posibilidad de variar el centro de percepción; así, la gran tarea de Don Juan es la de convencer al antropólogo de que la razón que éste tanto aprecia es solamente un centro de percepción, un modo de testimoniar el mundo, un modo válido y muy útil, pero no el único posible (Castaneda, 2000: 33).

¿No sería ésta una gran lección para la antropología? Lo que en definitiva se afirma es que la ciencia y la magia son modos diferentes de conocimiento, de acción y transformación; modos diferentes de "poder" cuya traducción implica traición y, por tanto, la inutilidad de reducir la magia a explicaciones de carácter científico. De cualquier manera, entender las limitaciones de la antropología como modos de saber y de experimentación vinculados al pensamiento científico y al pensamiento occidental como un todo, no implica negar su importancia; como ya hemos dicho, la antropología, así como la razón, es un instrumento de traducción, de mediación, de "pasaje" por entre varias descripciones posibles que entrañan varios "mundos" o realidades diferentes. Entender las limitaciones de la antropología es sorprenderse consigo mismo y relativizar la dimensión objetiva a la que nos aferramos como un náufrago se aferra a cualquier objeto que lo mantenga en la superficie; es relativizar nuestros objetos, no en el sentido de transformarlos en símbolos, en significados diversos que giran alrededor de un significante oculto e inaprensible, sino en relativizarlos al entenderlos como relaciones variables y transformadoras.

\section{Membresía}

La premisa básica de la brujería en los términos planteados por Don Juan es que la realidad es únicamente "una descripción", un modo de hablar de las cosas, un "fluir interminable de interpretaciones perceptibles que nosotros, como individuos que comparten una membresía $a^{2}$ específica, hemos aprendido a realizar en común" (Castaneda, 2001b: 9). Y, si la realidad como descripción es algo que se aprende, podremos entonces llegar a ser miembros de grupos definidos por otras descripciones, como por ejemplo, la de los brujos del México Antiguo a cuyo linaje pertenece Don Juan. En esto consiste el aprendizaje de Castaneda: adquirir "membresía" en el conocimiento de Don Juan; conocer una "nueva descripción del mundo" (Castaneda, 2001b: 15). Para esto el antropólogo deberá prescindir de una de sus premisas más preciadas, la de que existe una 
realidad subyacente y fidedigna, y que la ciencia es el modo de experimentación que más nos aproxima a ella. Sin pretender desvalorizar los esfuerzos del conocimiento occidental en la búsqueda de verdades huidizas y a veces universales.

A continuación hago un análisis crítico de las repercusiones del modo de actuación derivado de esa explicación filosófico-científica del mundo, utilizando como contrapunto el modo de actuar implícito en una descripción mágica del mundo conforme a los postulados de Don Juan. Para realizar esta tarea, mudamos las palabras que traducen conceptos y desviamos así el punto de vista, escogiendo como recomienda Roy Wagner un "conjunto de imágenes" (imagery), que "nos ayude a ver mejor el paisaje" (1981: XIX). Tal "conjunto de imágenes" (imagery), en nuestro caso, es la que Don Juan posibilita a Castaneda al describir uno de los conceptos centrales de su realidad: el Tonal, que será la base de nuestra reflexión, para comprender mejor no solamente la visión del mundo de Don Juan, sino también la nuestra.

No es una empresa fácil intentar definir el Tonal. Puedo hacerlo colocándolo en oposición al Nagual, pues, como dice Don Juan, el Tonal y el Nagual forman el único par verdadero; ambos constituyen la "totalidad de uno mismo" (Castaneda, 2001c). No obstante, es conveniente tener cuidado con este modo dicotómico de reflexión que nos es tan caro. Todo entendimiento, toda reflexión, toda oposición son efectos del Tonal; este es su modo de actuar, como quiero mostrar en este trabajo. Me abstengo de hablar del Nagual, una vez que el Nagual es aquello sobre lo que no podemos hablar, puesto que no hay palabras o nombres que puedan abarcarlo. El Nagual no tiene límites y nunca acaba, ni siquiera después de la muerte. Sólo podemos acceder al Nagual por medio de sus efectos; sólo podemos ser "testigos de sus efectos" (Castaneda, 200lc: 188). Así, el habla (lenguaje) y la razón son los modos con los que contamos para testimoniar el Tonal, pero no nos sirven para acceder al Nagual. Y es justamente este el punto central de la presente argumentación: existen diversos modos de percepción, modos de relación, de los cuales el habla (lenguaje) y la razón son sólo algunos de ellos, los modos por excelencia de percepción del Tonal. Otros serían el "soñar", el "ver" y el "sentir", que estarían ligados directamente a la "voluntad", el modo de testimonio del Nagual.

Pero las pretensiones de este artículo no son definir estos modos de percepción y/o de acción, pues tal tarea requiere un trabajo mucho más amplio, pero también, y sobre todo, porque la vía del entendimiento siempre será insuficiente cuando hablamos de estas cuestiones; así, más allá de buscar definiciones que nos permitan comprender estos modos, de lo que se trata es de saber, según los postulados de Don Juan, que como seres humanos podemos usarlos todos y que los hombres comunes, también llamados por él brujos malignos, ${ }^{3}$ nos caracterizamos por nuestro exagerado énfasis en la razón y el lenguaje y nuestra ignorancia de las práctica, de las técnicas, del "soñar", el "ver" y el "sentir". Esta elección es un compromiso, como veremos a lo largo del artículo. Comprender cómo llegamos a establecer este compromiso, cuáles vías, en cuáles gestos y entendimientos, es la tarea que me propongo, con la conciencia de que supera las posibilidades de este trabajo. Quizás puedo decir que encuentro vías que podemos intentar, y esto gracias a los trabajos de Carlos Castaneda y al conocimiento que Don Juan pacientemente le transmite a su cuerpo. Tras las aterradoras incursiones a los efectos del Nagual, el aprendiz de guerrero vuelve a ser Carlos Castaneda al inscribir en sus cuadernos los sentidos que produce y que le producen. El Tonal entra en acción y recrea los límites que le contienen y permiten. Esta es la metáfora de la aventura antropológica de Carlos Castaneda. Con este concepto del Tonal y sus modos de acción en mente, intentaré en lo que sigue mostrar sus posibilidades y potencialidades epistémicas. Veamos lo que dice el "informante". 


\section{El Tonal}

Para Don Juan, El Tonal es el "organizador del mundo" (Castaneda, 2001c: 163), el responsable de ordenar el caos y de crear el sentido que permite la comunicación; es todo aquello de lo que podemos hablar, el constructor de todo lo que conocemos y hacemos como hombres (Castaneda, 2001c: 163). Digamos que el Tonal, que es una "herramienta perceptiva" (Castaneda, 2001c: 354), es el encargado de establecer coordenadas espacio/temporales, cortes que son como fotografías, modulaciones, actualizaciones. Estos son los efectos del Tonal, aquello que genera el sentido y los significados.

El Tonal es la "persona social" (Castaneda, 200lc: 162), somos nosotros mismos, una vez que es el Tonal quien inventó la propia noción del yo, para poder hablar de sí (Castaneda, 200lc: 176). Todo cae bajo su dominio, puesto que él "está hecho de sus propios hechos" (Castaneda, 2001c: 164), y se obliga a sí mismo a seguir sus propios juicios (Castaneda, 2001c: 176), asumiendo los papeles de creador y criatura. En las palabras de Don Juan:

\section{El Tonal construye el mundo sólo en un sentido figurado. No puede crear ni cambiar nada y sin embargo construye el mundo porque su función es juzgar, y evaluar, y atestiguar. Digo que el Tonal construye el mundo porque atestigua y evalúa al mundo de acuerdo con las reglas del Tonal. De una manera extrañísima, el Tonal es un creador que no crea nada. O sea que, el Tonal inventa las reglas por medio de las cuales capta el mundo. Así que, en un sentido figurado, el Tonal construye el mundo (Castaneda, 200lc: 166-167).}

El Tonal, al igual que el Nagual, sólo es perceptible en sus efectos, lo que imposibilita su definición, como ocurre con el concepto de realidad o de mundo que poseemos. El mundo tal como lo conocemos es un producto del Tonal y quizás lo interesante sea comprender el modo de comprensión, antes que comprender el mundo en sí. Don Juan nos cuenta que comprender, o sea "juzgar, "evaluar", "atestiguar" el mundo, es tarea del Tonal. El Tonal atestiguando, evaluando y juzgando determina formas, nos determina como formas, lo que podemos comprender como el proceso de diferenciación, el establecimiento de separaciones, la significación de las distancias. "El Tonal es una isla" (Castaneda, 2001c: 167), un espacio delimitado por la inmensidad del océano y es también el protector y guardián de esa isla. "Astuto y celoso", protege "nuestro propio ser", la posibilidad de encontrarnos en determinada forma, en este también determinado mundo (Castaneda, 2001c: 163). El Tonal protege nuestra vida, es su posibilidad; "empieza en el nacimiento y acaba en la muerte” (Castaneda, 2001c: 165).

Nuestras vidas son producto de la acción de tonales individuales, modos de ser determinados por la percepción/invención del tiempo y/o modos de estar determinados por la percepción/actualización del espacio. El Tonal "hace" la vida —el estado del ser- definiendo fronteras, formas y posibilidades: definiendo límites. Hacer vida, parafraseando a Roy Wagner (1981), es actualizar la diferencia, inventar formas, escudos, límites que nos permitan sobrevivir a la relatividad, a la relación, a la alteridad y al otro transformador y transformacional. La vida no es lo dado, y lo más probable es que no encontremos nada dado en este juego de variación, que encontremos únicamente una constante redefinición de interiores y exteriores, como pide Latour (2004), de límites que sustancien las acciones, los gestos, las relaciones. De esta manera el Tonal vehicula lo posible de la vida tal y como la experimentamos, la actualización, el aquí y ahora, la asignación de un tiempo y un espacio para la forma.

El Tonal se manifiesta en diferentes tonales colectivos o tonales de los tiempos. Compartimos tonales en la medida en que nos involucramos en formas temporales específicas. El modo de conocimiento del Tonal de nuestro tiempo, o el modo de inventar y experimentar límites que nos caracteriza (por lo menos 
a los llamados "occidentales") es el modo de la dialéctica; un juego tautológico que le permite experimentar, explicar y entenderse a sí mismo: el modo del espejo. Este es el tipo de juego de nuestro Tonal colectivo para inventar "las reglas por medio de las cuales capta el mundo" (Castaneda, 2001c: 167). El Tonal juega consigo mismo, emparejando sus creaciones, inventando relaciones y denominándolas oposiciones y el "diálogo interno" es el modo en el que cada uno de los tonales individuales renovamos constantemente nuestro compromiso a jugar este juego según las mismas reglas. Don Juan explica:

La atención del Tonal tiene que colocarse en sus creaciones. De hecho esa atención es la que por principio de cuentas crea el orden del mundo; el tonal debe prestar atención a los elementos de su mundo con el fin de mantenerlo, y debe, sobre todo, sostener la visión del mundo como diálogo interno (Castaneda, 2001c: 309).

A través de la razón y del habla, que son centros de percepción o "modos de atestiguar" el Tonal, pensamos, nombramos, encarnamos y expresamos con nuestros gestos habituales los intervalos; y son estos intervalos, estas diferenciaciones, estas significaciones el modo en que la razón y el habla se experimentan también a sí mismas. La razón piensa el habla, que habla de la razón; la razón que puede de este modo aislarse en el interior de la representación, del pliegue. Nuestro Tonal Colectivo establece intervalos y levanta límites y fronteras imaginarios a los cuales aferrase con la fuerza de la fe y la creencia. Queda así resguardado de las posibles, constantes y múltiples relaciones con los otros, pues un Tonal que no se relaciona demasiado es un Tonal que no se transforma y, por tanto, que dura. El modo de permanencia de nuestro Tonal Colectivo transforma el "poder" en conocimiento cultural: conocimiento que reposa perenne en el lugar que el cuadro, el libro, las bibliotecas y los museos le otorgan. Allí es donde podemos sentirlo, donde encontramos nuestro lugar de testigos: el sujeto, el modo de ser de nuestro Tonal Individual. Testigo atento y comprometido, creador y criatura que juega el juego de los espejos.

Nuestra palabra, el movimiento de nuestro pensamiento, recorre y torna permanente el circuito de un interior supuestamente aislado al cual, como sujetos que somos, nos sujetamos. Es el diálogo interno con el que mantenemos la descripción del mundo que todos nosotros, hombres comunes, compartimos. A cada momento interpretamos lo que vemos, oímos, sentimos o percibimos a través del diálogo que establecemos con nosotros mismos. El modo que escogemos para interpretar, reitera nuestro compromiso con el modo de percepción que define nuestra "membrecía", nuestro compromiso con un tipo de sociedad o cultura. Digamos, para facilitar nuestra comprensión del asunto, que nuestra cultura y nuestra sociedad, al menos en cuanto conocidas por nuestra episteme, son el Tonal de "nuestro" Tiempo; determinados modos de ser y de estar en el espacio y en el tiempo que Wagner, en otro contexto, explica como "estilos de creatividad" o modos de "inventar el sí mismo [self] y la sociedad" (1981: 26 y 117), modos de percepción, finalmente. Considero que intentar comprender la mutua caracterización del Tonal Individual y el Tonal Colectivo, puede contribuir a la comprensión de la relación entre individuo y sociedad que tantas reflexiones antropológicas ha suscitado.

\section{Escenificando}

Uno de los principales efectos del Tonal de nuestro tiempo es que delimita la posibilidad de acción de los tonales individuales. Y uno de sus modos de hacerlo es ofrecernos el guión de nuestra interpretación en los escenarios donde representamos, incansablemente, las distintas versiones de los mitos elaborados por los "filósofos sabios" que, como dice Latour (2004), son los que determinan el modo occidental de analizar el mundo a partir de la distinción entre "hechos" y 
"valores". Somos actores, más que autores, escenificando una realidad que no deja mucho espacio para la improvisación.

Al seguir los postulados de Wagner (1981), vemos que estamos comprometidos con un modo de ver, con un punto de vista, y que ajustamos nuestras percepciones a una descripción determinada, transitando entre los distintos contextos, de acuerdo con intenciones prefabricadas, percibiendo e interpretando uno de los dominios como el resultado de ellas (acción humana), en cuanto que el otro aparece, al contrario, como su causa o motivación (innato). El compromiso del actor consiste, pues, en restringir su visión (1981: 44), al entender el mundo como dicotómico, al diferenciar el deseo de sus modos de actualización; al prescindir de su voluntad y sus opciones personales para poder actuar de acuerdo con los papeles que los otros han inventado para él. Por esta razón el actor, en este contexto, es un hombre limitado.

Foucault nos ayuda a conocer los límites porosos de este actor, de esta persona, o sujeto, o brujo maligno, que él llama hombre. Estos límites se manifiestan conceptualmente en forma de vida, de trabajo y de lenguaje: son las "positividades" que siempre en retroceso, "rondan en los límites exteriores de nuestra experiencia" (1999: 336). Realidades ejecutoras que dan forma a la experiencia, a la percepción, definiendo el punto de vista con el cual debemos comprometernos, ya que somos actores en este escenario del saber, cuyos "modos fundamentales" (Foucault, 1999: 347) adoptamos como únicos posibles. Finitud de la producción, unidad escondida de la vida bajo la transitoria multiplicidad de los seres, designación de acciones, estados y voluntades por el lenguaje (Foucault, 1999: 353, 369, 400): he aquí los instrumentos categóricos del Tonal para cerrar las fronteras que solamente debería guardar, para poder instaurar el intervalo convencional que haga posible la significación. El Tonal del hombre común, del actor, se engaña al negar lo ilusorio de las realidades o significaciones, concebidas de esta manera. Resulta tan importante definir, dar forma y delimitar, establecer un interior y un exterior, capaces de instaurar una dialéctica interminable, que nuestro Tonal prefiere entregarse a este vicio tautológico a libertarse y abrir su percepción al misterio sin fin del que forma parte.

Y así nuestro Tonal elige, inventa un hombre que lo habite, que sea el espacio dual donde se distinguen un adentro y un afuera; referencia crucial para su construcción frenética de pares a partir de sí. Foucault, como ya vimos, nos ayuda a descubrir ese modo de acción, ese hombre moderno, ese espacio dual cuyo límite inmanente se manifiesta como "finitud", "abertura para la posibilidad de todo límite concreto" (1999: 434); concretizar límites, he aquí la tarea fundamental de toda finitud. La vida, el trabajo, el lenguaje, las "positividades" que determinan al hombre, son "formas concretas de la existencia finita" (Foucault, 1999: 436): límites, concretización de formas, determinación, o sea, demarcación, fin, final del hombre moderno. Son modos que el Tonal de nuestro Tiempo utiliza para organizar sus fronteras, sus aberturas, sus deseos. Foucault (1999: 433-434) no cesa de afirmarlo: el hombre moderno es una abertura. ¿Abertura del deseo? iClaro! Sellada por el espacio del cuerpo, determinada por el tiempo del lenguaje, estado del ser. Vivir, trabajar, hablar en tiempos y espacios predeterminados, limitados, demarcados, finitos, esto es lo que hacemos: estos son nuestros "escudos". Y nosotros, los actores, "los hombres comunes", dejamos que estos quehaceres, estos escudos, estas ilusiones necesarias "dominen y derrumben nuestras vidas" (Castaneda, 2001a: 253), limitando nuestra experiencia e inmovilizando nuestro ser al otorgarle su nombre personal.

Nuestro modo de ser Tonal individual queda reducido al compromiso con el Tonal de nuestro tiempo. Somos actores, hombres, personas: los "mismos", los objetos de la "mismificación". Todos con el mismo compromiso de ser bizcos (como dice Latour, 2004), de dividir la experiencia en un par de dominios diferentes, para poder observar los límites 
que nos mantienen en nuestros lugares. Estos límites son las "positividades" de que nos habla Foucault (1999) y también, las máscaras, los títulos, las posiciones, papeles, propiedades, nombres, derechos y funciones que sobreviven a nuestra finitud, como recuerda Mauss a respecto de la "persona" (2003). Perpetuar los nombres asegura la duración de las cosas y de las almas (Mauss, 2003: 377), al menos en la memoria.

La "persona", como el actor y el hombre común, es la invención de un doble, la repetición de las dicotomías: la separación del espíritu y la naturaleza, dice Duvignaud (1979: 84). "A partir de las "personas" se ordenan los gestos de los actores en un drama" (Mauss, 2003: 375). Gestos; ¿de qué otro modo referirnos a la acción? La cultura es una "red de movimientos concertados" (Duvignaud, 1979: 116). Movimientos de duración... Duración y memoria que proclaman la Historia, o el "modo de ser fundamental de las empiricidades", como lo "inevitable" del pensamiento moderno; tan inevitable que se convierte en algo estanco, duración inmóvil (Foucault, 1999: 300, 356). Este es nuestro compromiso con un modo de acción, de actuación, de actualización. Somos demasiado sólidos; metáforas de hueso, de lo que permanece. Nuestros gestos son nuestro testimonio. "Seguimos los movimientos y figuramos un significante" (Duvignaud, 1979: 37).

Don Juan mostró a Castaneda el artificio, la trampa que nos lleva a confundir el mundo con lo que hacemos en él o de él (Castaneda, 200la: 219); confusión que, como alerta Duvignaud, compromete nuestro cuerpo (1979: 37). Los papeles, las funciones el "conjunto de movimientos ligados a actos definidos", retiran del cuerpo su disponibilidad. (Duvignaud, 1979: 27). Hablamos de hábitos, de rutinas que son modos de actuación, de la acción predefinida, predeterminada, mecánica y monótona que nos hace previsibles. En otras palabras, las rutinas resultan de lo convencional de determinados modos de acción que simbolizan el sujeto, lo referente, lo significante, el "ser estando" en objeto referido, significado, el "estado del ser". Las rutinas son las cristalizaciones del hacer con las que inventamos la familiaridad del mundo y acabamos confundiendo el mundo con lo que hacemos de él. Quedamos así presos al cuerpo ordenado, al cuadro cerrado, a los gestos predefinidos en el guión convencional. El cuerpo se vuelve forma, metáfora de un discurso estructurado. Somos actores bizcos en el escenario de la naturaleza única; hombres modernos que ocupan el lugar de lo finito, de lo acabado, de lo sólido, de la memoria. "Experiencia de una especialidad irreductible", dice Foucault (1999: 443), significación sedimentada. Nuestros cuerpos se consolidan en los límites que inventamos para contenerlos: la vida, el trabajo, el lenguaje. "Positividades" que son para nosotros una "costra dura", formada poco a poco, gracias a las innúmeras repeticiones de gestos y actos, dotados siempre de una función, de una funcionalidad (Duvignaud, 1979). Nuestra imagen permanece como reflejo de los límites que nos rodean, las "positividades" y los objetos que estas producen, son los espejos de los que decidimos rodearnos. Ellos nos devuelven una imagen cierta, definida e, incluso, en colores, no de lo que somos, sino de lo que de nosotros hacemos. Imagen de nuestro modo de ser en el tiempo y en el espacio.

Vemos así cómo hacerse actor, hombre común, "persona" es comprometerse con la construcción de un mundo común, con la definición de un exterior definitivo y, por medio de los gestos, de las acciones cotidianas transformadas en hábitos, experimentar la sustancia como solidez, inventando la realidad de un mundo cerrado en el cual permanecer tranquilo. Un mundo acabado, un "escudo" para disfrazar el misterio y su acción transformadora. He aquí una marca de nuestra relación con la finitud. En la esencia somos durables e indiscutibles, dice Latour (2004:376), pero la apariencia se angustia delante de la multiplicidad de posibles reflejos, de los vericuetos que el lenguaje recorre dentro de los muros de la ciudad que lo encierran. "Lenguaje empotrado en la extensión urbana de múltiples transformaciones internas" (Duvignaud, 1979: 71). 
En ella, en la ciudad, proliferan las máquinas de los tiempos modernos. Máquinas de transformación, como toda máquina. De transformación controlada y enmascarada de los hábitos en esencias (Latour, 2004 238), de las "positividades" en límites que contengan la variación, que enmascaren la finitud. Máquinas de producir formas duraderas, de hacerlas irreversibles; formas duraderas que legitiman la propia durabilidad, el modo de producir tiempos modernos (Latour, 2004: 309 y 376). Las máquinas de producir tiempos modernos, producen metáforas que "establecen sociedades"; metáforas y sociedades que son como las reglas del "juego de un espejo" (Duvignaud, 1979: 91). Punto de vista que crea un objeto: perspectiva de la máquina ${ }^{4}$ cuyos reflejos penetran en nuestros sentidos hasta que el hábito se vuelve esencia y nuestros cuerpos adoptan los objetos como su límite inmanente y necesario; objetos que "detienen el tiempo, inmovilizan la duración, tejen la tela del sistema cultural [...] que escapan a la disolución general, a la muerte" (Duvignaud, 1979: 66). Objetos que nos tornamos (Wagner, 1981: 138), objetos en los que el tiempo reposa en forma de memoria inmortal. El pecado hizo de nuestra alma algo espeso (Foucault, 1999: 25), por eso escogemos como reflejo la durabilidad.

\section{El cuerpo del sentido}

Jugamos el juego de la duración y hacemos del mundo un escenario donde podamos escenificar nuestro compromiso. Escenario de la vida en el que jugar el juego del doble, inventando pares que se remiten mutuamente: empírico y trascendental, esencia y apariencia, cualidades primeras y cualidades segundas, hechos y valores, naturaleza universal y cultura relativa, innato y acción humana, semejanza y diferencia, "dicotomía universal del hueso y la carne" (Duvignaud, 1979: 80), elementos de nuestro pensamiento, realidad actualizada por la acción estrábica de los actores, miembros comprometidos con un modo de descripción: la representación, el modo de lo doble, la "fuente principal de infección" (Latour, 2004: 78).

Se me ocurre suponer que el Tonal de nuestro Tiempo, el Tonal Occidental, posee la debilidad del narcisismo. El problema no es la tautología o la dialéctica, puesto que son formas del juego; el problema es la perfección del sentido que tal juego tiene para nosotros, pues difícilmente conseguimos o mejor, queremos, cambiar las reglas. La significación es una ilusión necesaria como afirma Wagner (1981). Ilusión que inventa haces y lugares, contextos. Rotulamos, es decir, nombramos a la relación de sentido, a la asociación de símbolos, realidad y así, organizamos el mundo para poder habitarlo. Construir sentido, fabricar significado es crear y experimentar contextos, ambientes de relación y relacionales; producir relaciones convencionales que permitan la comunicación, el diálogo, el entendimiento.

Los contextos son los términos del convencionalismo de las relaciones entre elementos diferentes, estructuras de significación, ambientes donde los elementos encuentran un lugar. Practicar el sentido es, en este caso, realizar una opción, definir lugares para las cosas y asignarles una duración, una actualidad permanente; es dividir el mundo en pares opuestos, concebir el orden posible delante del caos, definir las fronteras, los límites, las formas que la vida necesita, las "positividades" que la sitúan, que actualizan el ser del tiempo en el estar del espacio (estado del ser). Como afirma Viveiros de Castro, el sentido es la "realidad de lo posible en cuanto tal", efectuación de lo posible exprimido en el lenguaje o en el signo (2001: 08).

Se trata de la efectuación del "intervalo", que es prerrogativa del modo de ser del espacio y del tiempo de nuestro Tonal Colectivo, puesto que el "intervalo" es lo que nos permite pensar el espacio en cuanto límite o limitado y querer un tiempo durable, la duración. Foucault explica el intervalo, el pliegue que nos caracteriza como la "distancia ínfima pero invencible que reside en el "y" del retroceso y del 
retorno, del pensamiento y de lo impensado, de lo empírico y de lo trascendental, de lo que es del orden de la "positividad" y del orden de los fundamentos" (Foucault, 1999: 470). Es aquí, en este intervalo donde se define la relación espacio/tiempo de la perspectiva, el "punto" del "punto de vista", el haz epistémico que nos esclaviza y nos vuelve bizcos después de invitarnos sutilmente a estar comprometidos con él, ya que somos nosotros, hombres modernos, "filósofos-sabios", brujos malignos, actores y personas, los únicos capaces de darle cuerpo y de mantener su duración. Duración del tiempo en el espacio (ser) y del espacio en el tiempo (estado) estado del ser. El Tonal Individual de nuestro tiempo, demasiado endurecido, se contenta con pensar y hablar y repetir el juego tautológico de los pares, el juego de los pliegues: pliegues del pensamiento, del mundo, de las convenciones, del hombre, persona y actor. Pliegues del Tonal de nuestro tiempo. Pliegues del tiempo y del espacio que el Tonal inventa sin cesar. Nuestros límites, "positividades" y fronteras actualizan el pliegue del espacio en el tiempo o del tiempo en el espacio, actualizan el tiempo y el espacio como pliegue, intervalo haciendo posible el "cuadro" que permite al pensamiento "ordenar" las semejanzas y las diferencias, que permite al lenguaje entrecruzarse con el espacio y crear el "lugar" donde lo continuo del tiempo puede llegar a reposar, a durar (Foucault, 1999: XII). Lugar como "tabla de trabajo" (Foucault, 1999: XII), suelo favorable, fecundo de "positividades" (de vida, trabajo y lenguaje) que posicionan la mirada, determinando y delimitando la acción y la atención. ¿Con qué explicación ocupar el intervalo? Con la del lugar, el cuerpo instituido, determinado, situado, significado por el lenguaje-figuración de un significante.

¿Qué decir de nuestros cuerpos habituales y occidentales? Actualizar, incorporar o crear un cuerpo para el hombre, el actor, el sujeto, significa comprometerse con una determinada relación tiempo/ espacio, con un modo de conocimiento, con una perspectiva, con un punto de vista: el tiempo continuo de la virtualidad viene a reposar en el intervalo, en el pliegue, en el hueco, en el "lugar", en lo discontinuo del espacio. Lo que el modo de duración quiere detener es el movimiento del devenir o la velocidad de la percepción, el sentir en fin, para así limitar lo que sería un desplazamiento a la permanencia estática. Actual permanente - que es lo contrario de "actual momentáneo", de la actualización de la diferencia como pasaje - en la forma acabada y definida por las "positividades" y fronteras. Los términos son, en este modo, anteriores a la relación, productos de un poder pensado, de una fuerza dimensionada. La oposición y la dicotomía son inventadas como realidades universales, recorridas incansablemente por la dialéctica. La naturaleza de lo semejante y la culturización de las diferencias, encuentran aquí su razón de ser.

Los límites que dan sentido al mundo son necesarios, pero no por eso hemos de otorgarles el estatuto de verdad inquebrantable. Como afirma Don Juan: "Nuestro error es que insistimos en permanecer en nuestra isla, monótona y fastidiosa, pero conveniente. El Tonal es el villano y no debería serlo" (Castaneda, 2001c: 210). El intervalo del orden es constantemente perturbado por el caos de un universo que no acaba de comprometerse con la estructura. El Nagual acosa al Tonal y le recuerda constantemente que sus límites son solamente fronteras y su tiempo es más bien flujo que duración. Aunque el Tonal se aferre a la dialéctica que le permite jugar consigo mismo, la distancia nunca acaba de actualizarse, ya que, como afirma Lévi-Strauss, la conjunción y la disyunción (movimientos de lo continuo y de lo discreto), no son de hecho oposiciones, antes, una engendra a la otra en un juego de cambios y simetrías entre significado y significante (Lévi-Strauss, 2004: 364); o entre cualidades primeras y segundas, sujeto y objeto, hechos y valores, naturaleza y cultura, continuo y discontinuo.

Don Juan explica pacientemente a Castaneda que el problema que tenemos las "personas", los hombres 
comunes, los actores, es que somos esclavos de la razón (Castaneda, 2001a: 299), del compromiso con el estrabismo, con la dicotomía y la dialéctica del intervalo, que nos proporciona la falsa esperanza de perdurar. Entender, explicar e incluso experimentar son los modos de inventar el pliegue. "Si dices que entiendes mi conocimiento no has hecho nada nuevo", afirma enfático Don Juan (Castaneda, 2001a: 296). Los hombres comunes, los actores, pasamos la vida moviéndonos entre dos puntos, el habla y la razón y a este movimiento lo llamamos entendimiento. Don Juan avisa a Castaneda: "Tu problema es que quieres entenderlo todo y eso no es posible" (Castaneda, 200la: 296). La razón y el habla (lenguaje) son solamente dos posibilidades. Los hombres somos capaces de "manejar", que no es lo mismo que entender, ocho puntos que son como ocho mundos diferentes. Pero, limitados por el compromiso con un único modo, dicotómico y dialéctico, de ser en el tiempo y estar en el espacio, nos contentamos con el entendimiento, ignorando e incluso negando otras posibilidades de saber, otros modos de conocimiento que escapan a la razón y al lenguaje.

No somos el único modo de Tonal que habita el mundo y ni siquiera nuestro modo occidental es el único modo humano. Existen otros tonales colectivos, otros posibles modos de estar en el mundo, de actualizar fronteras e imágenes, fachadas; otros modos de acción. Tomando como ejemplo los "estilos de creatividad" de que habla Roy Wagner (1981) podemos percibir que nuestro Tonal Colectivo inventa sociedades formadas, pensadas, experimentadas y entendidas por personalidades que actúan en un mundo del cual no son autores, ya que su "motivación" no es propiedad suya, no les pertenece; en cuanto otros tonales colectivos inventan asociaciones de humanos cuya motivación no está separada de su acción. La perspectiva adoptada es un compromiso y los compromisos difieren, así como las máscaras y las personas a ellas asociadas. El hombre de conocimiento, el guerrero que fue lo más lejos posible en la caza al poder, aquel que cambia junto con las descripciones, es una extraña figura para los filósofos-sabios que permanecen en el mismo puente, aquel que va del mundo de los hechos al mundo de los valores, perdurando en la memoria y protegiendo el poder de su pensamiento con la "policía epistemológica" de que nos habla Latour (2004), pues el "poder" de los hombres de conocimiento es el poder del movimiento, de lo que circula, aquel que en este nuestro mundo sirve principalmente para enseñar a alguien más a guardar el "poder".

Don Juan que sabe de lo quimérico de cualquier duración, es la figura que se ríe de los filósofos-sabios desde las estanterías de auto-ayuda esotérica, lugar al que fueron relegados él y Castaneda. El acertijo es que el maestro no enseña al antropólogo el modo de comprender el mundo, pensarlo o explicarlo, puesto que el propio modo del antropólogo consigue realizar este trabajo. El maestro enseña al aprendiz a "parar el mundo", parar la descripción, salir del circuito cerrado de los reflejos de la palabra y de la razón. Para eso el aprendiz debe convertirse en un cazador de poder, un guerrero, alguien que "tiene" poder: poder de tirar del Tonal, de des-comprometerse con el lugar ocupado, con la forma, con el límite, con el punto de vista, con su concepto de cuerpo, sin sucumbir.

Lo que Don Juan enseña a Castaneda se resume a las técnicas para "parar el mundo" y adquirir poder, puesto que el poder personal es lo que permite al guerrero no comprometerse con cualquier descripción dada (Castaneda, 2001b: 193). La llave del poder no es solamente el conocimiento, a pesar de ser esta una forma de poder. La llave del poder es apropiarse de la propia percepción a través de los actos; he aquí por qué los actos de un guerrero "tienen poder". El poder personal, el estado de ánimo impecablemente afinado según los acordes de la voluntad más íntima del guerrero, es lo único que él posee en este mundo, que es un misterio sin fin (Castaneda, 2001c: 233) y el modo de acción del 
guerrero es esa afinidad de su ánimo con el ánimo del poder. La acción del guerrero es fluir, estar presente en el "momento" (Castaneda, 2001c: 19), perseguir el poder hasta que el mundo tal como lo conocemos haya dejado de existir (Castaneda, 2001c: 151) - "derribar el mundo" (Castaneda, 2001b: 193). Con confianza y abandono el guerrero siente el poder en sí y este poder le permite deshacer el mundo, para rehacerlo después y continuar viviendo (Castaneda, 2001c: 193). El modo del poder, como nos enseña Don Juan, es un "estado de ánimo", el sentir que descoloca, que desordena el sentido, el "ánimo del guerrero". Guerrero que es un cazador de poder, un cazador solitario que necesita prescindir, momentáneamente del sentido sociable y acogedor, para poder transitar por entre las descripciones. Perder el sentido, procurar el sinsentido, la "línea de fuga" de que nos hablan Deleuze y Guattari (1997) fluir por entre las descripciones; es el modo de sentir el mundo y no el modo de darle sentido lo que permite tener la fuerza necesaria para sobrevivir sin necesidad de estar comprometido con un punto de vista, con un modo de acción, determinado. Cazar el poder no pensando el sentido, ya pasado, mas sintiendo el estado de ánimo presente. El modo del guerrero es la alternativa al modo del actor, de la persona, del hombre común. Para experimentar la "brujería" de Don Juan, Castaneda precisa abstenerse del sentido y sentir el poder; es así como Castaneda deja de ser antropólogo y se convierte en otro, nativo, aprendiz, brujo... O puede ocurrir incluso, que sea el hecho de ser antropólogo lo que le permite mudar el compromiso, mudar la perspectiva, el modo de "inventar" sujetos, o el modo de inventarse sujeto, de sujetarse a la invención. Al librar el cuerpo del quehacer cotidiano, de lo que lo limita, del compromiso con la razón y el lenguaje, Castaneda, el antropólogo guerrero, aprende a "parar el mundo", haciendo posibles otros modos de percepción. Aunque siempre pegado a su diario de campo, que es el camino de vuelta, su escudo.

\section{Oposición y pasaje}

Siendo modos diferentes de conocimiento y de acción, podemos también comprender la ciencia y la magia como modos diversos de percepción. El conocimiento científico progresa "enmendando grietas", como afirma Lévi-Strauss (2003: 33), suprimiendo desvíos, o sea, recorriendo intervalos y ocupando lugares. El conocimiento mágico no progresa: el conocimiento mágico es un "pasaje". Esta es la gran diferencia. La magia no es simbólica, ni representación, puesto que ella niega el intervalo. La magia es del orden de lo continuo. Realiza un "pasaje"; ese es su modo de actuación y por consiguiente su "orden de lo real". La magia está intermediando la oposición del pensamiento y es precisamente esta intermediación el campo más fértil que puede encontrar la antropología dedicada al estudio de la magia. Una antropología dispuesta a trabajar del lado fluido de la ciencia, dispuesta incluso a transformarla y con ella transformar también los conceptos de lo real y de lo humano que transmite (a pesar muchas veces de sus propios resultados), tarea a la que se dedican autores de las más diversas áreas.

Don Juan nos enseña que las técnicas que Castaneda debe aprender si desea convertirse en un guerrero, pueden ser entendidas como modos a través de los cuales la persona, o actor, adquiere fluidez; al flexibilizar los límites que la definen, las máscaras que la constituyen; al deshacer el compromiso con el modo específico de explicar el mundo que el lenguaje y la razón trasmiten; al proceder de acuerdo con su voluntad más íntima; al librarse de las cadenas de una norma que la expropió de su motivación, de su deseo, de lo que en ella significa movimiento. Cuando el intervalo, el pliegue, el hueco, son fisura, brecha, "pasaje", las posibilidades se multiplican y se desvela la transformación inmanente a la relación. Fluidez de las formas, materia que es energía, dinamismo. Existen siempre otras relaciones no actualizadas, posibles; son múltiples los centros, las esencias, así 
como las naturalezas. Podemos, finalmente, imaginar los "pluriversos" de Gabriel Tarde; he aquí nuestra alternativa a la dialéctica, como dice Latour (2004: 137 nota 22): en lugar de exterioridad, interpenetración recíproca (Tarde, 2007b: 79). El exterior es un "estado interno" (Tarde, 2007b: 68), puesto que los límites, las fronteras, son relativos, esto es, relacionales. "Los tipos son solamente frenos y las leyes apenas diques opuestos en vano al transborde de las diferencias" (Tarde, 2007b: 106). Las formas que se presentan a nuestra percepción culturalmente codificada, los significados, los sentidos, los centros, los haces, los cuerpos, son momentos del movimiento, del "desplazamiento gradual" de una materialidad viva y activa (Tarde, 2007b: 61).

La esencia no es la materia o la sustancia, sino la actividad. Ocupar un lugar, actualizar un estado: la monadología renovada de Gabriel Tarde hace posible, "certifica bajo condición", que experimentemos conceptualmente un cuerpo como asociación de "esferas de acción" que "están por entero allí donde actúan" (Tarde, 2007b: 80). La materia es una sensación, una percepción, un modo. Los límites de la materia, el tiempo y el espacio, son "casi-sensaciones", lugares de traducción. Dice Tarde: la fuerza y la forma son "números exteriores de nuestras dos 'cantidades interiores": la creencia y el deseo (Tarde, 2007b: 71). De la forma a la fuerza y de la fuerza a la forma, el cuerpo, realidad de lo material, es una variación. En el no-lugar de la sensación sin sentido, el guerrero de límites fluidos se abre a la "perspectiva del otro", parafraseando a Viveiros de Castro (1996); con la brújula del deseo y la persistencia de la creencia. El guerrero lleva hasta las últimas consecuencias los "posibles" de Tarde: "existir es diferir" y "durar es mudar" (Tarde, 2007b: 98 y 136).

Si el modo de la acción es la fluidez y no la duración, entonces el "estar" es un pasaje, más que la ocupación de un lugar en un cuadro predefinido. Entretanto, como defiende Viveiros de Castro para el caso de la etnología amerindia y que me resulta una imagen fecunda en el contexto del presente análisis, es el "punto" lo que crea el sujeto, lo que permite la actualidad de la perspectiva, el cuerpo. El Tonal define el modo de ser en el tiempo y de estar en el espacio; es el modo de vida, como ya hemos dicho antes. Y para permanecer vivos necesitamos actuar, trasformar gestos en hábitos y compartir el "sentido" que limita los sentires, que cierra las brechas. La identidad y la semejanza afloran en los hábitos (Viveiros de Castro, 2001: 11), en los gestos convencionales y convenidos, y los hábitos, así como las descripciones, pueden variar. Será necesario, en tanto, estar muy bien preparados, puesto que "solamente los chamanes, personas "multinaturales" por definición y oficio, son capaces de transitar por entre las diversas perspectivas, tuteando y siendo tuteados por las subjetividades extra-humanas, sin perder la propia condición de sujeto" (Viveiros de Castro, 1996: 135). El "punto de vista" del guerrero sería el "punto de mutación", de la "transmutación de perspectivas" (Viveiros de Castro, 2002: 467). Para mantener su propia vida, el guerrero juega el juego de diferir: diferenciarse de las "fuerzas" que lo cercan en el misterio pavoroso y sin fin. El modo impecable de actuar del guerrero, es lo posible de la variación. Parafraseando a Tarde (2007b: 67), por sus "facultades de creer y desear" el guerrero accede a los "modos de creencia" y "modos del deseo" de las múltiples agencias que actúan sobre él.

Lo real es, pues, la acción, y la acción es el "efecto del deseo, siempre un cambio" (Tarde, 2007c: 135).

La acción y la actuación constituyen los márgenes del Tonal (Castaneda, 200lc: 191) y por tanto, cuanto más fluidas sean mayores serán las posibilidades de relación y variación. El tiempo y el espacio inventan la duración de la materia delimitando el yo a una forma finita; en cuanto a la forma de sensibilidad, "la creencia y el deseo", el "papel exterior del yo en relación a las sensaciones" (Tarde, 2007b: 68), o sea, el modo de fluidez material del yo, son también límites, pero límites cuya fluidez permite el pasaje, la variación constante. "Por la creencia el yo se distingue y distingue; por el deseo se modifica y modifica" (Tarde, 2007c: 135). La creencia es la fuerza que 
actualiza y por lo tanto, cualquier diferencia, contexto o norma, son un efecto de la creencia, mientras que el deseo es la voluntad de diferir, de variar, de mudar, la fuerza de lo virtualmente posible. El deseo es una "fuerza dinámica", que activa; la creencia es una "fuerza estática" (Tarde, 2001: 70).

Tanto la física como la vida son objetos de creencia (Tarde, 2007b: 70), y nosotros creemos poseer una "materia sólida" y de este modo nos relacionamos con ella (Tarde, 2007b: 125). Pero existen otros modos de creencia, otros modos de acción, otras actualizaciones posibles. Esto es lo que nos enseña el guerrero, que a diferencia del hombre común, del actor, cree en lo que cree, no porque conozca las verdades de fondo de todas las cosas, y mucho menos porque se sienta engañado en un océano de representaciones, sino porque sabe que las explicaciones son solamente explicaciones y que para saltar los muros del relativismo radical de tal percepción, o sea, para poder habitar los mundos que él habita, un guerrero tiene que creer en algo, debe comprometerse a cada momento y a cada movimiento, con alguna explicación, aún sabiendo que se trata únicamente de eso, de una explicación más, de otro posible compromiso. Así, el guerrero escoge creer de acuerdo con su voluntad más íntima; sin preocuparse de crear sentidos, se ocupa solo de sentir. El guerrero sabe que el sentido es únicamente un resguardo, una fachada, una máscara que lo posiciona, una ilusión necesaria, su punto de vista. Pero lo que le mueve es el gesto; el guerrero cree en su deseo... Su deseo de diferir.

\section{Asentir con la muerte}

iDiferir en la vida, flexibilizar los límites del Tonal! Un guerrero es aquel que aprende a morir, que está de acuerdo con la muerte, que se prepara para trabar la última batalla:

"Pedir consejo a la muerte, muda nuestro sentido de duración" y por tanto, del tiempo; saber que no hay tiempo que perder hace con que el guerrero actúe en todo momento como si su acto presente fuese el último y en razón de eso da siempre lo mejor de sí (Castaneda, 200lb:127-128).

Los actos de un guerrero tienen poder (Castaneda, 2001b: 125) porque él invita a la muerte a ser testigo de sus acciones, de su estado pasajero, de su diferencia mutable. El guerrero danza para la muerte, este es su tributo; la danza es la coreografía que narra sus luchas, los gestos que durante su paso por la tierra evitaron que fuese devorado por una perspectiva ajena. La lucha es sentir, intercambiar y guardar el poder que le permitirá continuar, una vez más, el juego de la transformación. Ser perecedero por un instante (Duvignaud, 1979: 126), en este preciso momento; llegar en vida a la totalidad de sí mismo; he aquí la gran tarea que solamente un espíritu impecable es capaz de emprender. Un espíritu impecable, la conquista de un guerrero, el resultado de sus acciones, como lo son todas las otras variedades y cualidades de espíritus y las realidades que los reflejan. Un espíritu impecable que también "se hace", pero, aprendiendo a "no hacer".

Asentir con la muerte no significa abolir o negar la vida; asentir con la muerte no es una fuga, la proyección trascendental de una "sustancia coherente y sólida, satisfecha y reposada" (Tarde, 2007b: 70), que se representa a sí misma en los mismos espejos que le permiten perdurar. He aquí la visión de la máquina dual (Deleuze y Guattari, 1997), de la máquina de la opacidad que produce objetos finitos y proyecta nuestra finitud en los objetos, ${ }^{5}$ transformándose así en nuestros propios espejos. Nuestra visión se adaptó a la duración del objeto, a su inmovilidad y en razón de eso, nuestra mirada es rígida; es el precio que pagamos por los resguardos que nuestro Tonal elige, junto con una imagen de fragilidad frente a la muerte inevitable. Creemos que podemos controlar el misterio sin fin que es el mundo, con nuestros quehaceres de hombres comunes, con nuestras realidades indiscutibles y objetivas y con el poder que 
nos otorga el conocimiento. También para el guerrero el conocimiento puede transformarse en poder, pero no en forma de permanencia, en la inmovilidad de estanterías donde se acumulan palabras y polvo, hasta que alguien venga a retirarlas del lugar.

En el mundo habitado por el guerrero "cada trocito de conocimiento que se vuelve poder tiene a la muerte como fuerza central (Castaneda, 200la: 173). Un guerrero "asiente" con la muerte, lo que no significa entregar el juego y romper los espejos en un desmedido impulso de inquietud, puesto que un guerrero es alguien que jugando a discrepar, escoge los elementos que forman su mundo, los espejos que lo reflejan y que, con mucho esfuerzo y de un modo impecable, equilibra su espíritu y fortalece su Tonal personal, luchando para vivir, para disfrutar todavía un poco más en el "camino con corazón" que decidió recorrer. El "camino con corazón" es la apropiación de la opción, de la elección, el modo de pasar por el mundo, en el mundo, de un hombre que asintió con la muerte. El placer increíble de realizar cada acto, disfrutar de cada momento, dando lo mejor de nosotros mismos y transformando en "poder mágico nuestro tiempo ordinario sobre la tierra" (Castaneda, 2001a: 173); el modo de aquellos que hacen de la muerte su mejor consejera, que consienten escucharla y sentirla:

Sólo la idea de la muerte da al hombre el desapego suficiente para que sea incapaz de abandonarse a nada. Sólo la idea de la muerte da al hombre el desapego suficiente para que no pueda negarse nada. Pero un hombre de tal suerte no ansía, porque ha adquirido una lujuria callada por la vida y por todas las cosas de la vida. Sabe que su muerte lo anda cazando y que no le dará tiempo de adherirse a nada, así que prueba, sin ansias, todo de todo. Un hombre desapegado, sabiendo que no tiene posibilidad de poner vallas a su muerte, sólo tiene una cosa que lo respalde: el poder de sus decisiones. Tiene que ser, por así decirlo, el amo de su elección. Debe comprender por completo que su preferencia es su responsabilidad y una vez que hace su elección no queda tiempo para lamentos ni recriminaciones. Sus decisiones son definitivas, simplemente porque su muerte no le da tiempo de apegarse a nada. Y así, con la conciencia de su muerte, con desapego y con el poder de sus decisiones, un guerrero arma su vida en forma estratégica. El conocimiento de su muerte lo guía y le da desapego y lujuria callada; el poder de sus decisiones definitivas le permite escoger sin lamentar, y lo que escoge es siempre estratégicamente lo mejor; así cumple con gusto y con eficiencia lujuriosa, todo cuanto tiene que hacer" (Castaneda, 200la: 174-175).

Los actos de un guerrero son una forma de pasar, los actos de alguien que sabe que la "continuidad" del hombre carece de "sentido", en este "mundo de pavor y misterio" (Castaneda, 2001b: 126). La arrogancia, la excesiva importancia que nos atribuimos a nosotros mismos y a nuestras invenciones, nos impide entender que el mundo a nuestro alrededor es un misterio sin fin, de manera que creemos que somos los únicos que pueden inventar los modos de estar en él; el resto de los seres, como no piensan o hablan, o como no piensan y hablan como nosotros, están limitados al reino de los hechos sin voz, de la motivación innata y por tanto sin posibilidad de elegir. Parecemos seres aislados en nuestro cubículo de verdades, ajenos a la diferencia radical de los otros modos de estar en el mundo, lo que empobrece, y mucho, nuestra experiencia de "diferir". "Perder la importancia" supone entender que somos, así como otros muchos, seres que van a morir; o sea, diferencia difiriendo, o diferir de la diferencia, parafraseando a Tarde (2007b). Tal posibilidad de acción se le abre al guerrero que aprende, a aquel que se compromete con el "conocimiento" de los chamanes del México Antiguo y establece una alianza conceptual con el "hecho energético" de que somos seres que vamos a morir, a mudar, a transformarse (Castaneda, 2000: 33). El guerrero que asiente con la muerte, con el infinito (2000: 33). 
Pero nosotros occidentales, hombres modernos, actores disfrazados, filósofos-sabios, fantasmas, tenemos una relación negativa con la muerte, pues, como dice Foucault (1999: 382), queremos creer que el polvo en que se deshacen "las grandes arquitecturas funcionales" es "polvo sin vida". iQué pretensión! El polvo, las partículas, los elementos en los que nos desmembramos, las mónadas, lo infinitesimal infinito de que nos habla Tarde (2007b), atestiguan el fin de la finitud ${ }^{6}$ (Foucault, 1999: 516), la ceguera de la perspectiva de perduración. La variación infinitesimal es el movimiento de lo aparentemente inmóvil, la fluidez inmanente de lo sólido, el "pasaje" de lo durable; percepción de lo imperceptible a los "ojos del fantasma" que, según Kopenawa, chamán yanomami, nos caracterizan a los "blancos" (Kopenawa apud Viveiros de Castro, 2007: 02). ${ }^{7}$ Variar es alterar, alterarse y ser alterado; es el modo de actuar del brujo, o del chamán, aquel que deja de ser fantasma después de haber sobrevivido al encuentro con el "aliado", ${ }^{8}$ que le da la velocidad necesaria para vibrar en sintonía con múltiples conciencias. Existe una gran diferencia entre las duraciones de los hombres comunes y los encuentros de guerreros, aunque tengamos por costumbre sacrificar los encuentros a las duraciones, como afirma Tarde (2007a: 189-190).

El guerrero, así como los chamanes de los que nos habla Viveiros de Castro (2007: 03), aprende a ser un "diplomático cósmico" buscando intencionadamente encontrar las "fuerzas inexplicables e inflexibles" que pueblan los mundos que él habita, recorriendo lo que en otro contexto Duvignaud (1979: 85) llama "laberintos de duraciones diversas" en la extensión del cosmos. Pero "encuentro" no quiere decir, en su caso, explicación o entendimiento, o modificación o control de las fuerzas. Un guerrero aprende a usar las fuerzas poderosas gracias al equilibrio que conquistó con su impecable voluntad (Castaneda, 200la: 246-247). " "Voluntad" que es el "centro" de percepción del Nagual, un modo de acción; un modo que se actualiza, que se realiza, gracias a la "fluidez" del Tonal del guerrero.
Los resguardos, escudos, fachadas, límites, son, parafraseando a Deleuze y Guattari (1997), modos de agenciamiento del Tonal, modos de individuación, de modulación de la velocidad de la percepción. Modos que los hombres comunes llamamos cuerpos, que interpretamos y experimentamos como cuerpo y muchas veces, como objetos delimitados a un espacio, inmóviles en el tiempo. Pero el guerrero fluido, que tuvo acceso al modo de la "voluntad", no quiere ya limitarse a datar el mundo cronológicamente y para él "el mundo y él mismo ya no son objetos” (Castaneda, 200lc: 67). El cuerpo de un guerrero, el organismo fluido, es un modo de organizar la experiencia perceptiva, un modo de sentir el mundo y la posibilidad de atestiguar el Nagual, de aprehender la alteridad. Cuerpo que es como un espejo, o una infinidad de espejos infinitesimales, de cristales pluridimensionales que reflejan la luz, el movimiento, en innumerables direcciones. Movimiento modulado por el filtro de una mirada, de un modo de apropiación, de actualización momentánea y pasajera. Movimiento del espejo, del "instrumento de pasaje entre las experiencias de la intensidad luminosa y de la innumerabilidad de los espíritus" (Viveiros de Castro, 2007: 19); espejo como medio de transporte, punto de vista, marca o modo de acción. Y cuando la acción es variación, ¿qué se puede ser además de imagen? El cuerpo es como un juego de espejos, compendio de cristales polifacéticos, multidimensionales, "pluriverso" en acción.

Según Viveiros de Castro el chamán, el "modulador de perspectivas", es alguien que "posee demasiados cuerpos" (2007: 11), demasiados espejos. Es, como los brujos y guerreros de los que aquí hablamos, alguien que percibe otros modos de organizar la energía, otros modos de conciencia, otras modulaciones de la vibración; alguien que "ve" los espejos infinitesimales de la floresta, los "cuerpos" de "xapiripë", que siempre "brotan de nuevo". Como dice Kopenawa, citado por Viveiros de Castro (2007: 20): "Nosotros no hacemos sino vivir entre los espejos de los espíritus; ...nuestra 
floresta pertenece a los xapiripë y está hecha de sus espejos".

"Ambigüedad trans-específica" de los chamanes (Viveiros de Castro, 2007: 06), los héroes de los mitos, los que pasan por entre los intervalos de la ciencia y sus modos de diferenciar lo semejante, sus modos de especiación. Si hay algo que oponer, cabría decir que el modo de actuar de los brujos del México Antiguo, del linaje de Don Juan, se opone a la creación de identidades simbólicas de los filósofos-sabios. Pues, a pesar de que la física occidental puede ser muy metafísica y de que sus representantes, sus traductores, experimentan velocidades de percepción usando "prótesis" que les permitan observar lo invisible, su función no es la misma. Ser chamán, como ser filósofo socrático, es un "funcionamiento", como dice Viveiros de Castro, (2007) pero ser funcional es, en el primer caso, ser impecable (Castaneda, 2000: 39) y en el segundo, razonable. El poder del pensamiento no es el poder personal que Don Juan enseña a Castaneda a cazar y guardar. El poder del guerrero es poder variar. El guerrero, como las mónadas de Tarde (2007b), están allí donde actúa; aquí y allí, a veces, en un mismo momento.

Diferentes Tonales son diferentes modos de acción y, por tanto, diferentes mundos. ¿Cuál es ese mundo que queremos habitar, nosotros los hombres modernos, absortos en la frenética construcción de máquinas que fabrican objetos? Nuestro mundo, nuestra invención cultural, ciertamente durará. Por lo menos, el tiempo necesario para la digestión de la materia, de los elementos del suelo y del subsuelo de la tierra que no dejamos de extraer y transformar en papeles, plásticos, metales y gases. Probablemente los objetos que fabricamos serán los testigos de nuestro final, como les pedimos que lo hagan. Este es el fin con el que nos comprometemos en lo cotidiano de nuestros hábitos. Pero existen otros posibles modos de nutrición, de variación, como podemos atestiguar en las entrelíneas, en las líneas de fuga del texto antropológico, de ese texto poblado de risas y "fiestas caníbales" (Duvignaud, 1979:
202). Castaneda lo demuestra al compartir la autoría de sus libros con Don Juan, al mantenerse fiel a sus palabras y conceptos. Conceptos que vehiculan ideas fundamentales para la reflexión antropológica, aun bajo el velo de la duda sobre su veracidad.

La función del guerrero devora la funcionalidad de la antropología de la duración. La muerte es un regalo, es dejarse comer. Como es un regalo la impecabilidad del guerrero; un regalo conquistado para el ser amado: la Tierra. Un guerrero es inaccesible, lo que significa "tocar lo menos posible el mundo que te rodea" (Castaneda, 2001b: 107), retirando del mundo solamente lo que necesita para pasar por él y masticando lentamente el poder de la muerte del otro, de la planta, del animal, del viento, del agua, de la tierra, de los elementos reunidos en ese "ser espléndido" que ama, que ha escogido para amar. La predilección del guerrero es la vida en la tierra.

\section{Notas}

${ }^{1}$ Dice Octavio Paz (2000: 12): “[...] el tema del saber está ligado al del poder y ambos a la metamorfosis".

${ }^{2}$ Es un concepto central en este trabajo. Hace referencia a ser "miembro" de un grupo, de una sociedad o una cultura con cuyo "punto de vista" estamos comprometidos.

${ }^{3}$ Este concepto es utilizado por Don Juan en Viaje a Ixtlán (2001b) Es una forma de referirse a hombres comunes, a aquellos que tienen potencialidad para ser brujos, pero que no la actualizan.

${ }^{4}$ Perspectiva: "posición de la realidad que especifica un sujeto" (Viveiros de Castro, 2001: 05).

${ }^{5}$ Como señala Foucault, la finitud y la producción se superponen en una figura única, la de la oposición entre la vida y la muerte (1999: 360).

6 "[...] una finitud sin infinito, es una finitud que nunca tiene fin" (Foucault, 1999: 516).

${ }^{7}$ A lo largo de este artículo estoy citando una versión provisional del texto Floresta de cristais, cedida por el autor en un archivo en PDF. Este texto fue publicado 
en la revista Caderno de Campo de la USP-Universidad de Sao Paulo, como referido en la bibliografía adjunta.

${ }^{8}$ Aliado: "un poder capaz de transportar a un hombre más allá de sus propios límites" (Castaneda, 2000: 253).

9 "En su última batalla sobre la tierra, el guerrero deja fluir su espíritu libre y claro. Y mientras libra su batalla, sabiendo que su voluntad es impecable, el guerrero ríe y ríe" (Castaneda, 200la: 248).

\section{Bibliografía}

Castaneda, Carlos (1968) 2000, The Teachings of Don Juan (a Yaki Way of Knowledge), Berkeley, University of California Press, Edição em espanhol, Las enseñanzas de Don Juan, Tradução de Juan Tovar, México: Fondo de Cultura Económica (Segunda edição).

Castaneda, Carlos (1971) 200la, A separate Reality (Further conversations with don Juan), Edição em espanhol, Una realidad aparte, México: Fondo de Cultura Económica (segunda edição).

Castaneda, Carlos (1972) 200lb, Journey to Ixtlan. The lessons of Don Juan, Edição em espanhol, Viaje a Ixtlán, México: Fondo de Cultura Económica (segunda edição).

Castaneda, Carlos (1974) 200lc, Tales of Power, Nueva York, Simon and Shuster. Edição em espanhol: Relatos de poder, México: Fondo de Cultura Económica (segunda edição).

Deleuze, Gilles e Guattari, Félix (1997), "Devir animal, devir intenso, devir imperceptível”, en Mil Platôs: capitalismo e esquizofrenia, vol. 4, São Paulo, Ed. 34.

Duviganud, Jean (1979), El sacrificio inútil, México: Fondo de Cultura Económica.

Foucault, Michel (1999), As palavras e as coisas: uma arqueologia das ciências humanas, São Paulo: Martins Fontes.

Latour, Bruno (2004), Políticas da natureza: comofazer ciência na democracia, Bauru: EDUSC.
Lévi Strauss, Claude (2003), "Introdução à obra de Marcel Mauss”, en Sociologia e Antropologia, São Paulo: Cosac \& Naify.

Lévi Strauss (2004), O cru e o cozido, São Paulo: Cosac \& Naify.

Mauss, Marcel (2003), "Uma categoria do espírito humano: a noção de pessoa, a de 'eu'”, en Sociologia e Antropologia. São Paulo: Cosac \& Naify.

Paz, Octavio (2000), "La mirada anterior", en Castaneda, Carlos, Las enseñanzas de Don Juan, México: Fondo de Cultura Económica.

Tarde, Gabriel (2007a), "A ação dos fatos futuros", en Eduardo Vianna Vargas (org), Monadologia e sociologia e outros ensaios. São Paulo: Cosac \& Naify.

Tarde, Gabriel (2007b), "Monadologia e Sociologia", en Eduardo Vianna Vargas (org), Monadologia e sociologia e outros ensaios, São Paulo: Cosac \& Naify.

Tarde, Gabriel (2007c), "A variação universal", en Eduardo Vianna Vargas (org). Monadologia e sociologia eoutros ensaios, São Paulo: Cosac \& Naify.

Viveiros De Castro, Eduardo (1996), "Os Pronomes Cosmológicos e o Perspectivismo Ameríndio", en Mana: Estudos de Antropologia Social 2/2, Rio de Janeiro: Museu Nacional - UFRJ.

Viveiros De Castro, Eduardo (2001), “A propriedade do Conceito", en Texto apresentado no Seminário Temático, "Uma notável reviravolta: antropologia (brasileira) e filosofia (indígena)”, Caxambu: ANPOCS, 2001.

Viveiros De Castro, Eduardo (2002), "Xamanismo e Sacrifício", en A inconstância da alma selvagem e outros ensaios de antropologia, São Paulo: Cosac \& Naify.

Viveiros De Castro, Eduardo (2007), "A Floresta de cristais: notas sobre a ontologia dos espíritos amazônicos", en Cadernos de Campo (USP), vol. 14-15.

Wagner, Roy (1981), The invention of culture, Chicago: University of Chicago Press. 